Multi-century Changes to Global Climate and Carbon Cycle: Results from a Coupled Climate and Carbon Cycle Model

G. Bala, K. Caldeira, A. Mirin, M. Wickett, C. Delire

February 18, 2005

Journal of Climate 
This document was prepared as an account of work sponsored by an agency of the United States Government. Neither the United States Government nor the University of California nor any of their employees, makes any warranty, express or implied, or assumes any legal liability or responsibility for the accuracy, completeness, or usefulness of any information, apparatus, product, or process disclosed, or represents that its use would not infringe privately owned rights. Reference herein to any specific commercial product, process, or service by trade name, trademark, manufacturer, or otherwise, does not necessarily constitute or imply its endorsement, recommendation, or favoring by the United States Government or the University of California. The views and opinions of authors expressed herein do not necessarily state or reflect those of the United States Government or the University of California, and shall not be used for advertising or product endorsement purposes. 


\title{
Multi-century Changes to Global Climate and Carbon Cycle: Results from a Coupled Climate and Carbon Cycle Model
}

\author{
G. Bala, K. Caldeira, A. Mirin, M. Wickett, and C. Delire* \\ Atmospheric Science Division \\ Lawrence Livermore National Laboratory \\ Livermore, CA 94550 \\ *ISE-M, Université Montpellier II \\ 34095 Montpellier cedex 5, France
}

(Submitted to Journal of Climate 3/14/05) 
UCRL-JRNL-209851

\begin{abstract}
In this paper, we use a coupled climate and carbon cycle model to investigate the global climate and carbon cycle changes out to year 2300 that would occur if $\mathrm{CO}_{2}$ emissions from all the currently estimated fossil fuel resources were released to the atmosphere. By year 2300, the global climate warms by about $8 \mathrm{~K}$ and atmospheric $\mathrm{CO}_{2}$ reaches 1423 ppmv. The warming is higher than anticipated because the sensitivity to radiative forcing increases as the simulation progresses. In our simulation, the rate of emissions peak at over $30 \mathrm{PgC} \mathrm{yr}^{-1}$ early in the $22^{\text {nd }}$ century. Even at year 2300 , nearly 50 $\%$ of cumulative emissions remain in the atmosphere. In our simulations both soils and living biomass are net carbon sinks throughout the simulation. Despite having relatively low climate sensitivity and strong carbon uptake by the land biosphere, our model projections suggest severe long-term consequences for global climate if all the fossil-fuel carbon is ultimately released to the atmosphere.
\end{abstract}




\section{Introduction}

Anthropogenic emissions of $\mathrm{CO}_{2}$ from fossil fuels and land use change are expected to lead to significant climate change in the future (IPCC 2001). Both climate change and elevated $\mathrm{CO}_{2}$ impact land and ocean carbon uptake. Photosynthesis by land plants is expected to increase with increased atmospheric $\mathrm{CO}_{2}$ content (the so-called $\mathrm{CO}_{2}$ fertilization effect) when water and nutrients are available (Owensby et al. 1999), leading to increased terrestrial carbon uptake. Increased global temperatures are expected to increase heterotrophic respiration rates (Lloyd and Taylor 1994), diminishing or even reversing the net $\mathrm{CO}_{2}$ flux from the atmosphere to the land biosphere (Cox et al. 2000; Friedlingstein et al. 2001; Cramer et al. 2001; Joos et al. 2001). Global warming is expected to reduce uptake of carbon by oceans (Sarmiento and Le Quere 1996; Sarmiento et al. 1998), because $\mathrm{CO}_{2}$ is less soluble in warmer water and increased stratification would inhibit downward transport of anthropogenic carbon.

Here, we use a three-dimensional coupled ocean/atmosphere climate/carbon-cycle general circulation models to study the feedbacks between the physical climate system and the carbon cycle. Cox et al. (2000) and Friedlingstein et al. (2001) described the first such models that represented the three-dimensional dynamical response of Earth's climate and carbon system to $\mathrm{CO}_{2}$ emissions. Cox et al. (2000) showed a very large positive feedback whereas Friedlingstein et al. (2001) showed a much weaker feedback. A feedback analysis by Friedlingstein et al. (2003) indicated that the differences between the model results were due primarily to Southern Ocean circulation and land carbon response to global warming. However, land response to climate change was the dominant difference between the two model simulations of the $21^{\text {st }}$ century. In the HadCM3 model (Cox et al. 2000), the land biosphere became a net source of $\mathrm{CO}_{2}$ to the atmosphere, whereas in the IPSL model (Friedlingstein et al. 2001), the land biosphere remained a net sink of $\mathrm{CO}_{2}$ from the atmosphere. 
UCRL-JRNL-209851

Zeng et al. (2004) performed a fully coupled carbon-climate simulation and several sensitivity runs for the period of 1860-2100 with prescribed IPCC SRES-A1B emission scenario. Their results also indicated a positive feedback to global warming from the interactive carbon cycle, with an additional increase of $90 \mathrm{ppmv}$ in the atmospheric $\mathrm{CO}_{2}$, and 0.6 degree additional warming. However, the changes in various carbon pools were more modest, largely due to the multiple limiting factors constraining terrestrial productivity and carbon loss. They suggest that the large differences among the models are manifestations of some of the poorly constrained processes such as the global strength of the $\mathrm{CO}_{2}$ fertilization effect and the turnover time and rates of soil decomposition.

Using an interactive climate and carbon cycle model, Thompson et al. (2004) attempted to bracket the uncertainty in terrestrial uptake arising from uncertainty in the land-biosphere $\mathrm{CO}_{2}$-fertilization effect. They performed one simulation in which the land-biosphere model was very sensitive to $\mathrm{CO}_{2}$ fertilization and another simulation in which the land uptake was restrained by limiting $\mathrm{CO}_{2}$ fertilization at present day levels. The fertilization-limited run was designed to represent the possibility that $\mathrm{CO}_{2}$ fertilization effect could saturate rapidly, perhaps due to nutrient limitations. Through year 2100, the land was a very strong sink of carbon in the $\mathrm{CO}_{2}$-fertilized simulation, but it became a source of carbon to the atmosphere in the fertilization-limited simulation. The predicted atmospheric $\mathrm{CO}_{2}$ at year 2100 differed by 336 ppmv between the two cases. In the fertilization-limited run, the vegetation biomass was stable, but the soil carbon pool was shrinking because of climate change-induced increases in heterotrophic respiration.

Using the same model, Govindasamy et al. (2005) studied the sensitivity of the carbon cycle feedback to climate sensitivity (amount of global warming per doubling of atmospheric $\mathrm{CO}_{2}$ concentrations). In that investigation, in the high-climate sensitivity case, year-2100 global warming was $8 \mathrm{~K}$ and land carbon uptake was $29 \%$ of total $\mathrm{CO}_{2}$ emissions; in the zero-climate-sensitivity case there was little warming and land uptake 
was $47 \%$ of total emissions. The atmospheric $\mathrm{CO}_{2}$ concentration increased $48 \%$ more in the run with $8 \mathrm{~K}$ global climate warming than in the case with no warming. These results indicated that carbon cycle amplification of climate warming would be greater if there were higher climate sensitivity to increased atmospheric $\mathrm{CO}_{2}$ content.

Previous coupled modeling studies without the carbon cycle component have mostly investigated doubled- $\mathrm{CO}_{2}$, quadrupled- $\mathrm{CO}_{2}$, and other $\mathrm{CO}_{2}$-stabilization scenarios. The recent coupled climate and carbon cycle models have focused on projection of climate change and the carbon cycle feedback over the $21^{\text {st }}$ century (Cox et al. 2000; Friedlingstein et al. 2001; Thompson et al. 2004; and Zeng et al. 2004). The recent modeling studies suggest that carbon-cycle consequences of global warming are likely to amplify the effect of $\mathrm{CO}_{2}$ emissions, because increased respiration rates at higher temperatures would induce carbon loss from the land biosphere to the atmosphere. These models have not been used previously to study the multi-century impact of largescale fossil fuel emissions on climate and the carbon cycle out to year 2300. Recent coupled modeling studies have suggested that the climate sensitivity to radiative forcing increases with time in long integrations (Senior and Mitchell 2000; Gregory et al. 2004), suggesting that warming in multi-century simulations will be larger than anticipated from the results of single century simulations.

In this study, we address the impact of releasing $\mathrm{CO}_{2}$ to the atmosphere by anthropogenic emissions from currently estimated fossil fuel resources by year 2300 on global climate and carbon dynamics. We use the coupled climate and carbon cycle model of Thompson et al. (2004). The major purpose is to investigate the time evolution of climate, carbon cycle feedbacks, and the fate of emissions of all available fossil fuels in such a long simulation. Our simulations indicate that eventual atmospheric release of $\mathrm{CO} 2$ from all fossil-fuel resources could produce about $8 \mathrm{~K}$ warming of global and annual mean surface temperature by year 2300 . We note that our results are from a single 
UCRL-JRNL-209851

modeling study and validation using other coupled climate and carbon cycle models is required.

\section{Model}

To investigate the long-term impacts of climate change due to anthropogenic emissions, we use INCCA (INtegrated Climate and CArbon), the coupled climate and carbon cycle model (Thompson et al. 2004; Govindasamy et al. 2005). The physical ocean-atmosphere model is the NCAR/DOE PCTM model (Meehl et al. 2004; Washington et al. 2000), which is a version of the NCAR CCM 3.2 model (Kiehl et al. 1996) coupled to the LANL POP ocean model (Dukowicz and Smith 1994; Maltrud et al. 1998). The climate model is coupled to a terrestrial biosphere model, Integrated Biosphere Simulator version 2 or IBIS2 (Foley et al. 1996; Kucharik et. al. 2000) and an ocean biogeochemistry model based on the Ocean Carbon-cycle Model Intercomparison Project (OCMIP) Biotic protocols (Thompson et al. 2004; Najjar and Orr 1999). The horizontal resolution of the land and atmosphere models is approximately $2.8^{\circ}$ in latitude and $2.8^{\circ}$ in longitude. The ocean model has a horizontal resolution of $(2 / 3)^{\circ}$. The atmosphere and ocean models have 18 and 40 levels in the vertical, respectively.

\section{Experiments}

We developed a year 1870 "pre-industrial" initial condition with more than 200 years of fully coupled equilibration before the start of experiments. During the first half of the spin up period, changes in soil carbon pools were accelerated by a factor of 40 . We perform two model simulations starting from the pre-industrial initial conditions: a "Control" case with no change in forcing for the period 1870-2300, and an "A2 Scenario" case in which both the amount of $\mathrm{CO}_{2}$ in the atmosphere and the impact of that radiative forcing on the climate system are calculated based on the IPCC SRES A2 emission scenario (IPCC 2001). 
UCRL-JRNL-209851

In the Control case, climate drift for the period $1900-2300$ is a $-0.62 \mathrm{~K}(\sim-0.15$ per century) change in mean surface temperature (Table 1), a 3.8 ppmv increase in atmospheric $\mathrm{CO}_{2}$ concentration, and an increase of $8 \mathrm{Gt}-\mathrm{C}$ in soil carbon. The drift in sea ice area and volume for this 400 year period are $+15.3 \%$ and $+40 \%$ respectively. Relative to the size of the perturbation in our experiments, the drift in global mean temperature over 400 years is small, yet sea ice is sensitive to this drift. In contrast, the carbon cycle model drift is over two orders-of-magnitude smaller than carbon cycle changes predicted in the A2 simulation.

In the $\mathrm{A} 2$ case, $\mathrm{CO}_{2}$ emissions (Fig. 1) are specified at historical levels for the period 1870-2000 (Marland et al. 2002) and at SRES A2 levels for the period 2000-2100 (IPCC 2001). For the period 2100-2300, emissions follow a logistic function for the burning of the remaining fossil-fuel resources (assuming 5270 gigatonnes of carbon (GtC) in 1750; Caldeira and Wickett 2003). Non- $\mathrm{CO}_{2}$ greenhouse gas concentrations are specified at historical levels for 1870-2000 and SRES A2 levels for 2000-2100 (IPCC 2001) and are fixed at 2100 levels thereafter. Land use emissions are taken from Houghton (2003) for the historical period and from SRES A2 scenario for the period 2000-2100 and set to zero thereafter. There is no change in aerosol forcing. In this scenario, total emissions reach 30.8 Gt-C per year around year 2120 from present day values of $8 \mathrm{Gt}-\mathrm{C}$ per year. The cumulative emission for the entire period 1870-2300 is 5404 Gt-C. Total emissions in $20^{\text {th }}, 21^{\text {st }}, 22^{\text {nd }}$, and $23^{\text {rd }}$ centuries are $385,1791,2558$, and $644 \mathrm{Gt}-\mathrm{C}$ respectively; the rate of emissions peak in the $22^{\text {nd }}$ century for this scenario and the emission rates decline sharply in the $23^{\text {rd }}$ century.

\section{Results}

\subsection{Global Climate change}

The evolution of non-drift-corrected global and annual means of surface temperature and atmospheric $\mathrm{CO}_{2}$ concentration is shown in Fig. 2. The global and 
annual mean transient climate responses are listed in Table 1. The centennial responses are computed by differencing the last and first decadal averages of the centuries. The climate drift from the control run is subtracted from our coupled run (Table 1). However, since the drift of the carbon cycle is negligible, we do not perform the subtraction for the carbon cycle variables. The global mean climate warms by $0.80,2.7,3.18$ and $1.15 \mathrm{~K}$ in the $20^{\text {th }}, 21^{\text {st }}, 22^{\text {nd }}$ and $23^{\text {rd }}$ centuries respectively (e.g. $20^{\text {th }}$ century climate change refers to decade of 1991-2000 minus 1891-1900). The total warming from 1870 to 2300 is about $8 \mathrm{~K}$. The warming is largest in the $22^{\text {nd }}$ century. Other responses like precipitation change, increase in atmospheric precipitable water, and decrease in sea ice extent are also largest in the $22^{\text {nd }}$ century when the emissions rates are the highest (Fig. 1).

The predicted atmospheric $\mathrm{CO}_{2}$ concentration also shows the biggest increase in the $22^{\text {nd }}$ century (Table 1 ). However, the sea ice volume shows the fastest decline the in $21^{\text {st }}$ century. Because of the large drift in sea ice ( $40 \%$ in 400 years) the drift-corrected total change (Table 1) appears more than $100 \%$, though the actual reduction was about $90 \%$. We find that the sea ice cover disappears almost completely in the southern hemisphere by year 2150 during southern hemisphere summers. The net radiative flux at the top of the atmosphere (TOA) increases by $0.93 \mathrm{Wm}-2$ in the $21^{\text {st }}$ century due to increase in the heat content of the system. It changes only a little in the $22^{\text {nd }}$ century, suggesting very little storage of energy in the system in this century. In the $23^{\text {rd }}$ century, net TOA flux starts decreasing because the fossil fuel emission rates are declining and the system is moving toward equilibrium with declines in heat content.

We find that the depth of meridional overturning circulation (MOC) in the Atlantic becomes weak and shallow with climate change in this model, with much of the deep North Atlantic filling up with water from the Southern Ocean. For pre-industrial period and present day, the circulation at $24 \mathrm{~N}$ fills the whole depth, $5.5 \mathrm{~km}$, of the North Atlantic Ocean. The depth of MOC is defined as the distance from the surface to where the water transport becomes zero. By year 2100, the depth of MOC is reduced to $3 \mathrm{~km}$. It 
is reduced further to $2 \mathrm{~km}$ by year 2300 . We also find that the amplitude of the global MOC shows nearly $30 \%$ weakening (30 to $20 \mathrm{~Sv}$ ) by year 2100 and it does not show significant decline afterwards.

Fig. 3 shows the evolution of radiative forcing and the global- and annual-mean surface temperature change as a function of radiative forcing in our coupled A2 simulation. We used the formulae from IPCC (1997) for the computation of radiative forcing of $\mathrm{CO}_{2}$ and other non- $\mathrm{CO}_{2}$ greenhouse gases, and adopted a value of $3.45 \mathrm{Wm}^{-2}$ for the radiative forcing due to a doubling of $\mathrm{CO}_{2}$ in this model. The climate sensitivity of the model is known to be $2.1 \mathrm{~K}$ per doubling of $\mathrm{CO}_{2}$ using a slab ocean model (IPCC 2001). Due to the thermal inertia of the oceans, the surface temperature has warmed only $2.25 \mathrm{~K}$ when the radiative forcing is $5 \mathrm{Wm}^{-2}$ (Fig. 3b). However, the warming becomes 8 $\mathrm{K}$ when the radiative forcing reaches about $10.5 \mathrm{Wm}^{-2}$. The larger warming in the latter half of radiative forcing can be partly explained by the thermal lag of the climate system. It is also partly due to the increase of climate sensitivity as the simulation progresses (Fig. 4; Senior and Mitchell 2000; Gregory et al. 2004); a radiative forcing of about $10.5 \mathrm{Wm}^{-2}$ would suggest an equilibrium warming of $6.3 \mathrm{~K}$ for this model, assuming an equilibrium climate sensitivity of $2.1 \mathrm{~K}$. However, the warming is $8 \mathrm{~K}$ and the climate system has not reached equilibrium yet. It is likely there will be further warming with no further increase in forcing (Fig. 3b) because of the thermal lag of the coupled climate system. Therefore, the warming is larger than expected from the results of single-century simulations or equilibrium simulations using a slab ocean version of the model.

The climate sensitivity plotted in Fig. 4 is the "effective climate sensitivity" as defined in Murphy (1995) and Senior and Mitchell (2000). Here, it is given as the amount of warming in Kelvin per doubling of $\mathrm{CO}_{2}$. The signal to noise ratio is much improved (Fig. 4) after year 2050 (or after a warming of $2 \mathrm{~K}$ ). Climate sensitivity is seen to increase from the model's previously known value of about $2 \mathrm{~K}$ to $3 \mathrm{~K}$, an increase of about $50 \%$. Senior and Mitchell (2000) found that the effective equilibrium climate sensitivity of 
UCRL-JRNL-209851

their coupled system increased by $40 \%$ in an 800 -year integration, and the timedependence was associated with differences in cloud feedback arising from interhemispheric temperature differences due to the slower warming rate of the Southern Ocean. An investigation on the cause for the increase of equilibrium climate sensitivity with time (or warming) in our model will be the subject of a future paper.

\subsection{Land and Ocean carbon fluxes}

The global and annual mean net land and ocean uptakes are shown in Fig.5. A 5yr running mean exhibits less variability. The model tends to slightly overestimate historical terrestrial carbon uptake estimates for the 1980s and 1990s based on observed intra-decadal trends in atmospheric $\mathrm{CO}_{2}$ and $\mathrm{O}_{2}$ (Prentice et al. 2000, 2001). The land uptake increases monotonically with time until year 2120 when the uptake is about $45 \%$ of the total emissions. The effect of $\mathrm{CO}_{2}$ fertilization is probably exaggerated in our simulation because we do not consider factors other than limitation by sunlight, water, and carbon dioxide. Compared to similar models, IBIS tends to simulate higher fertilization effect (Mc Guire et al 2001). Land uptake of carbon starts to decline in the $22^{\text {nd }}$ century when the emissions rates also begin to decrease. By year 2300 , it reaches levels close to zero because increased heterotrophic respiration (Fig. 6) offsets Net Primary Productivity (NPP).

Net land uptake is mainly NPP minus heterotrophic respiration $(\mathrm{RH})$. The ecosystem disturbances like fire are parameterized as $\mathrm{CO}_{2}$ sources to the atmosphere and their magnitude is only about $10 \%$ of NPP or RH. Net Primary Productivity and heterotrophic respiration show sharp increases during 2000-2150 and remain steady thereafter (Fig. 6 upper panel). The land uptake is mostly stored in biomass (Fig. 6 middle panel). The increase in the amount of biomass carbon is about $1300 \mathrm{Gt}-\mathrm{C}$ by year 2300 from its preindustrial value of about $700 \mathrm{Gt}-\mathrm{C}$. However, soil carbon shows only a modest increase of about $500 \mathrm{Gt}-\mathrm{C}$ because of a sharp fall in its turnover time (Fig. 6 
lower panel). The turnover times of biomass and soil carbon are obtained by dividing their masses by net-primary productivity and heterotrophic respiration, respectively. The newly produced carbon in the soil pool is labile and hence the turnover time of soil carbon is sharply reduced by year 2150 (Fig. 6 lower panel). Neither soil carbon nor biomass shows any decline during the entire simulation (Fig. 6 middle panel), and the land remains a sink for carbon throughout our A2 simulation (Fig. 5). However, a higher climate sensitivity could result in significantly increased soil microbial respiration and a decline in soil carbon (Govindasamy et al. 2005). If there is no additional CO2fertilization after the year 2000 level, then the soil carbon content could be declining by year 2100 (Thompson et al. 2004).

The ocean uptake increases to about 4 Gt-C per year, peaking after year 2100 , following the pattern of $\mathrm{CO} 2$ emissions to the atmosphere (Fig.5). The uptake reaches only a third of the land uptake. This may be an underestimate, as the model tends to underestimate historical ocean carbon uptake estimates (Prentice et al. 2001; Sabine et al. 2004) and model results from OCMIP (Orr and Dutay 1999; Orr et al. 2001). Like land uptake, ocean uptake also declines in the $22^{\text {nd }}$ and $23^{\text {rd }}$ centuries when the emissions rates are decreasing. This decrease in uptake is due to the warming of the surface ocean that drives enhanced $\mathrm{CO}_{2}$ fluxes out of the ocean (Sarmiento and Le Quere 1996; Sarmiento et al. 1998). Since the ocean time scales for reaching equilibrium are much higher than land time scales (Kheshgi 2004), the ocean uptake in year 2300, unlike land uptake, has not yet reached equilibrium though the emission rates are nearly zero in year 2300 . Therefore, the ocean continues to draw down $\mathrm{CO}_{2}$ beyond year 2300 .

\subsection{Carbon Cycle Feedback factor}

The "carbon cycle feedback factor" is defined as the ratio of $\mathrm{CO}_{2}$ change when climate is changing to the $\mathrm{CO}_{2}$ change when climate is constant (Friedlingstein et al. 2003). Here, it is the ratio between the $\mathrm{CO}_{2}$-change in our $\mathrm{A} 2$ experiment and that in a 
UCRL-JRNL-209851

zero-climate-sensitivity experiment. In the zero-climate-sensitivity experiment, the land and ocean carbon cycle models perceive the emissions and predicted atmospheric $\mathrm{CO}_{2}$ content, but the climate system perceives the preindustrial values of $\mathrm{CO}_{2}$ and other greenhouse gases. We extended the zero-climate-sensitivity experiment of Thompson et al. (2004) and Govindasamy et al. (2005) to year 2300.The carbon cycle feedback factor may depend on the carbon cycle processes (Thompson et al. 2004) and climate sensitivity (Govindasamy et al. 2005).

The implied net carbon cycle feedback factor in our simulations is 1.09 between 1870 and 2000 (Table 2). It increases to 1.13 for the period between 1870 and 2100 . The net carbon cycle feedback factors are $1.19,1.675$ and 1.24 for the same period in Friedlingstein et al. (2001), Cox et al. (2000) and Zeng et al. (2004), respectively. Therefore, our model shows the weakest feedback between climate and carbon cycle among the existing coupled climate and carbon cycle models. The feedback factor increases to 1.29 for $1870-2300$, the entire period of simulation. We believe that this increase is due to the reduction in the turnover time scale of the soil carbon pool with time (Fig. 6c), and because of an increase in climate sensitivity with time (see the discussion for Figs. 3 and 4). However, the increase in the feedback factor is small and it suggests near-linear behavior of the carbon cycle feedback factor over the 430 -year period.

\subsection{Fate of Anthropogenic Emissions}

Under the SRES A2 scenario, the total emission rate reaches $30.8 \mathrm{Gt}-\mathrm{C}$ per year at year 2120. The cumulative anthropogenic emission for the period 1870 to 2300 is 5404

Gt-C. The amounts taken up by land and ocean are shown in Fig.7. By 2300, the land biosphere takes up 2067 Gt-C, nearly 38 percent of the emissions. During the same period, oceans take $17 \%$ or $921 \mathrm{Gt}-\mathrm{C}$ of the emissions. The residual, $2416 \mathrm{Gt}-\mathrm{C}$ (45\%) stays in the atmosphere. The uptake fractions will depend on the amount of global 
warming; land uptake decreases from 47 to $29 \%$ of the total emissions as the global temperature change increases from 0 to $8 \mathrm{~K}$ in our model (Govindasamy et al. 2005). It will also depend on other assumptions; Thompson et al. (2004) demonstrated that terrestrial biosphere could become a source of carbon to the atmosphere by year 2050 if nitrogen/nutrient limitations limit $\mathrm{CO}_{2}$-fertlilization levels to that of year 2000 .

The partitioning of the emissions between the reservoirs (land, ocean and atmosphere) by century shows that the land and atmosphere take about $40 \%$ each of the emissions and the ocean takes up about $20 \%$ in the $20^{\text {th }}$ century (Table 3 ). The emissions and the uptakes by all reservoirs increase in the $21^{\text {st }}$ century and reach peak values in the $22^{\text {nd }}$ century and then show sharp declines in the $23^{\text {rd }}$ century. Fractional terrestrial uptake declines in $22^{\text {nd }}$ and $23^{\text {rd }}$ centuries presumably because of a warmer climate. Fractional oceanic uptake becomes smallest in the $22^{\text {nd }}$ century when the emissions rates are the highest even though the absolute amount of uptake is the largest for oceans. The slower response due to long ocean time scales is responsible for this behavior. Fractional atmospheric uptake reaches its peak value of $50 \%$ in the same period. It decreases to 27 $\%$ in the $23^{\text {rd }}$ century. Fractional oceanic uptake increases to $35 \%$ in the $23^{\text {rd }}$ century suggesting the role of oceans in the eventual uptake of anthropogenic emissions.

\subsection{Changes in Vegetation Distribution}

IBIS simulates the present day distribution of natural vegetation fairly realistically (Foley et al. 1996; Kucharik et. al. 2000) when forced with the observed climate. Dominant vegetation distributions from our simulations for the periods 1971-2000, 2071$2100,2171-2200$, and $2271-2300$, designated as $20^{\text {th }}, 21^{\text {st }}, 22^{\text {nd }}$ and $23^{\text {rd }}$ century vegetation distribution, respectively are shown in Fig. 8. We use kappa statistics (Monserud 1990) to compare maps of vegetation distributions. Kappa takes on a value of 1 with perfect agreement. It has a value close to zero when the agreement is approximately the same as would be expected by chance. A kappa value of 0.47 (fair 
agreement; Landis and Koch 1977) is obtained for a comparison of IBIS simulated vegetation and observations (Foley et al. 1996).

Global comparison of simulated $20^{\text {th }}$ century vegetation distributions with distributions of $21^{\text {st }}, 22^{\text {nd }}$ and $23^{\text {rd }}$ centuries give kappa values of 0.61 (good agreement), 0.40 (fair) and 0.32 (poor) respectively. In terms of area occupied by different vegetation types, tropical and temperate forests expand significantly with global warming (Fig.8; Table 4). The area covered by them increases from about $45 \%$ in the $20^{\text {th }}$ century to nearly $65 \%$ of the land area in the $23^{\text {rd }}$ century. In general there is a migration of tropical, temperate, and boreal forests pole ward with warming, leading to significant declines in the area occupied by tundra and polar deserts (land ice) by year 2300. Interestingly, the fraction of deserts shows a decline of about $4 \%$ by year 2300 . The large increase in biomass (Fig. 6 middle panel) and hence the land carbon uptake (Table 3 and Fig. 5 and 7) is due to the vegetation dynamics, with forested ecosystems with higher biomass replacing grasslands, shrub land and tundra.

These results don't take into account the constraint land use puts on the development of natural ecosystems. In our simulations, we only account for the global carbon emissions due to land use by using Houghton's (2003) estimate for the historical period, the SRES A2 scenario for the period 2000-2100 and zero thereafter. We do not actually simulate crops with IBIS and the model set up allows natural vegetation to grow everywhere. However, forests won't be able to grow as simulated here because a large part of the land surface will be under some form of cultivation (Ramankutty et al 2002). This would limit carbon uptake by the land biosphere because most cultivated ecosystems don't accumulate biomass and under current management practices, very little litter enters the soil. In summary, Fig. 8 shows only the potential vegetation distributions at the end of each century; it does not include the human-induce land use changes. We also caution that climate change and $\mathrm{CO}_{2}$ fertilization could also impact ecosystem goods and services not represented by our terrestrial ecosystem model, such as species abundance 
UCRL-JRNL-209851

and competition, seed dispersal, habitat loss, biodiversity and other disturbances (Root and Schneider 1993).

\section{Discussion}

In this paper, we have investigated global climate change and carbon budget out to year 2300 that would occur if $\mathrm{CO}_{2}$ emissions from all the currently estimated fossil fuel resources were released to the atmosphere. Emissions from the SRES A2 scenario are used to year 2100. For the period 2100-2300, emissions follow a logistic function for the burning of the remaining fossil-fuel resources. In our emission scenario, it is assumed that about $5000 \mathrm{Gt}-\mathrm{C}$ is available as fossil fuel in year 2000 (with about $270 \mathrm{Gt}-\mathrm{C}$ emitted before then). In our model, the climate warms by $8 \mathrm{~K}$ by year 2300 . This warming is higher than anticipated because of an increase in climate sensitivity as the simulation progresses. Of the total fossil fuel and land-use change emissions of $5400 \mathrm{Gt}-\mathrm{C}$ for the period $1870-2300$, about $38 \%$ and $17 \%$ are taken up by land and oceans, respectively and the remaining $45 \%$ stays in the atmosphere. Atmospheric $\mathrm{CO}_{2}$ concentrations are 257 ppmv higher in the fully coupled simulation than in the no climate change run. The carbon cycle feedback factor shows an increase from 1.09 to 1.29 when global warming increases from 0.8 in year 2000 to $8 \mathrm{~K}$ in year 2300 . Even though our model has relatively lower climate sensitivity among the climate models (IPCC 2001) and weak carbon cycle feedback, our results suggest severe long-term consequences for global climate if $\mathrm{CO}_{2}$ emissions from all the currently estimated fossil fuel resources were released to the atmosphere.

Our land carbon cycle model remains a net sink for carbon in the atmosphere even when the warming is as high as $8 \mathrm{~K}$ at year 2300. In HadCM3 (Cox et al. 2000), carbon in Amazonian vegetation begins to decline by year 2050, as a drying and warming of Amazonia initiates forest loss. Such a loss of vegetation biomass does not occur in our simulations; in contrast, the amount of biomass carbon nearly triples in our simulation by 
year 2300. In our simulation, soil carbon increases throughout the simulation. However, either less $\mathrm{CO}_{2}$-fertilization or higher climate sensitivity could result in increased soil microbial respiration and decreased soil carbon reservoir in this model (Govindasamy et al. 2005; Thompson et al. 2004).

In the real world, as opposed to our model, $\mathrm{CO}_{2}$-fertilized ecosystems may run into nutrient limitations. The high sensitivity of our terrestrial biosphere model to added $\mathrm{CO}_{2}$ might be associated with the lack of nutrient cycles (e.g., nitrogen, phosphorous, etc.). Changes in nitrogen availability are important to the carbon cycle through changes in plant nutrient availability (Schimel 1998; Nadelhoffer et al. 1999; Shaw et al. 2002; Hungate et al. 2003). Models that include nitrogen limitation show less sensitivity of $\mathrm{CO}_{2}$ fluxes for changes in atmospheric $\mathrm{CO}_{2}$ (Cramer et al. 2001). Even without nutrient limitations, the enhanced physiological effects of $\mathrm{CO}_{2}$ on productivity and water use efficiency asymptote at high $\mathrm{CO}_{2}$ concentrations (Farquhar et al. 1980; King et al. 1997; Cao and Woodward 1998). Our terrestrial biosphere model also lacks acclimation of soil microbiology to higher temperature (Kirschbaum 2000; Tjoelker et al. 2001). We have not simulated realistic land use in order to correctly account for the differences between crops and natural ecosystems.

As in most carbon cycle/climate studies, we assumed constant aerosol forcing in our simulations. If all fossil fuel reserves are to be used by year 2300, it is likely that oil and gas burning will be replaced by coal burning, coal reserves being much larger than oil and natural gas (International Energy Outlook 2004). And the switch from oil and gas burning to coal burning is likely to be associated with changes in aerosol emissions, as well as methane and black carbon emissions. The net effect of these changes is hard to estimate as they depend on the type of coal and development and availability of clean technology. It is likely however that the overall effect will accelerate warming. In a reverse study, Hayhoe et al. (2002) showed that a switch from coal to natural gas in the utility sector could result in an initial warming phase followed by a cooling trend. The 
UCRL-JRNL-209851

initial warming is due to the decrease of $\mathrm{SO}_{2}$ emissions and the following decrease to the lower emissions of $\mathrm{CO}_{2}$ and black carbon.

The results of this fully coupled climate-carbon model indicate that the carbon cycle feedback factor and the fraction of anthropogenic $\mathrm{CO}_{2}$ that stays in the atmosphere will slightly increase as the planet warms. Our previous studies (Thompson et al. 2004; Govindasamy et al. 2005) using this model have shown that the carbon cycle feedback is sensitive to terrestrial carbon-cycle processes (e.g. $\mathrm{CO}_{2}$ - fertilization and respiration) and climate sensitivity about which we are uncertain at present. These uncertainties could perhaps be narrowed with investigation of carbon dynamics across a broad range of ecosystems and climate regimes, often including manipulation experiments, and redoubled efforts to represent those dynamics in climate models. Nevertheless, despite these uncertainties, our model projections indicate the potential for severe long-term consequences for global climate if all the fossil-fuel carbon is ultimately released to the atmosphere.

\section{Acknowledgements}

This work was performed under the auspices of the U.S. Department of Energy by the University of California Lawrence Livermore National Laboratory under contract No. W7405-Eng-48.

\section{References}

Caldeira, K., and M. Wickett, 2003: Nature, 425, 365.

Cao, M., and F. I. Woodward, 1998: Dynamic responses of terrestrial ecosystem carbon cycling to global climate change, Nature 393, 249-252.

Cramer, W., A. Bondeau, F. I. Woodward, and Coauthors, 2001: Global response of terrestrial ecosystem and function to $\mathrm{CO} 2$ and climate change: results from six dynamic global vegetation models, Global Change Biology 7, 357-373. 
UCRL-JRNL-209851

Cox, P. M., R. A. Betts, C. D Jones, S. A. Spall, and I. J. Totterdell, 2000: Acceleration

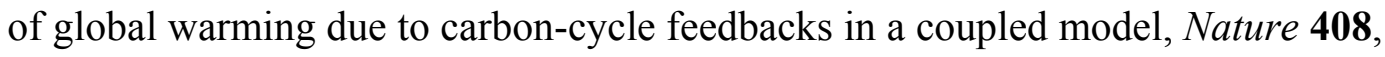
184-187.

Dukowicz, J. K., and R. D. Smith, 1994: Implicit free-surface method for the Bryan-CoxSemtner ocean model, J. Geophys. Res. 99, 7991-8014.

Farquhar, G.D., S.V. Caemmerer and J.A. Berry, 1980: A biochemical-model of photosynthetic $\mathrm{CO}_{2}$ assimilation in leaves of C-3 species, Planta, 149, 78-90.

Foley, J. A., I. C. Prentice, N. Ramankutty, S. Levis, D. Pollard, S. Sitch, and A. Haxeltine, 1996: An integrated biosphere model of land surface processes, terrestrial carbon balance and vegetation dynamics, Global Biogeochem. Cycles 10, 603-628.

Friedlingstein, P., L. Bopp, P. Clais, and Coauthors, 2001: Positive feedback between future climate change and the carbon cycle, Geophys. Res. Lett. 28, 1543-1546.

Friedlingstein, P., J.-L. Dufresne, P. M. Cox, and P. Rayner, 2003: How positive is the feedback between climate change and the carbon cycle? Tellus 55B, 692-700.

Govindasamy, B. S. Thompson, A. Mirin, M. Wickett, K. Caldeira and C. Delire, 2005: Increase of carbon cycle feedback with climate sensitivity: Results from a coupled climate and carbon cycle model. Tellus B (in press).

Gregory, J. M., W. J. Ingram, M. A. Palmer, G. S. Jones, P. A. Scott, R. B. Thorpe, J. A. Lowe, T. C. Johns, and K. D. Williams, 2004: A new method for diagnosing radiative forcing and climate sensitivity, Geophys. Res. Lett., 31, L03205.

Hayhoe K, H. S. Kheshgi, A. K. Jain, D. J. Wuebbles, 2002: Substitution of natural gas for coal: Climatic effects of utility sector emissions, Climatic Change, 54 (1-2): 107-139.

Houghton, R., 2003: Revised estimates of the annual net flux of carbon to the atmosphere from changes in land use and land management 1850-2000, Tellus 55B, 378-390. 
UCRL-JRNL-209851

Hungate, B. A., J. S. Dukes, M. R. Shaw, Y. Luo, and C. B. Field, 2003: Nitrogen and Climate Change, Science 302, 1512-1513.

Intergovernmental Panel on Climate Change (IPCC), 1997: An introduction to simple climate models used in the IPCC second assessment report, IPCC Technical paper II, J. T. Houghton, L. G. M. Filho, D. J. Griggs, and K. Masket (eds.), IPCC, Geneva, Switzerland.

Intergovernmental Panel on Climate Change (IPCC), 2001: Climate Change 2001, The Scientific Basis, Cambridge University Press, New York, USA.

International Energy Outlook, 2004: Rep. no. DOE/EIA-0484 (2004), Energy Information Administration, Office of Integrated Analysis and Forecasting, U.S. Department of Energy, Washington, D.C.

Joos, F., I. C. Prentice, S. Sitch, and Coauthors, 2001: Global warming feedbacks on terrestrial carbon uptake under the Intergovernmental Panel on Climate Change (IPCC) emission scenarios, Global Biogeochemical Cycles 15, 891-907.

Kheshgi, H. S., 2004: Ocean carbon sink duration under stabilization of atmospheric $\mathrm{CO}_{2}$ - A 1000-year time scale, Geophys. Res. Lett., 31, L20204, doi:10.1029/2004 GL020612.

Kiehl, J. T., J. J. Hack, G. B Bonan, B. Y. Boville, B. P. Briegleb, D. L. Williamson, and P. J. Rasch,1996: Description of the NCAR Community Climate Model (CCM3). NCAR Tech. Note. NCAR/TN-420+STR, National Center for Atmospheric Research, Boulder, Colorado.

King, A. W., W. M. Post, and S. D. Wullschleger, 1997: The potential response of terrestrial carbon storage to changes in climate and atmospheric $\mathrm{CO} 2$, Climate Change 35, 199-227.

Kirschbaum, M.U.F. 2000, Will changes in soil organic carbon act as a positive or negative feedback on global warming? Biogeochemistry, 48, 21-51. 
UCRL-JRNL-209851

Kucharik, C. J., J. A. Foley, and Coauthors, 2000: Testing the performance of a dynamic global ecosystem model: Water balance, carbon balance, and vegetation structure, Global Biogeochem. Cycles 14 (3), 795-825.

Landis, J. R., and G. G. Koch, 1977: The measurement of observer agreement for categorical date, Biometrics 33, 159-174.

Lloyd, J. and J.A. Taylor, 1994: On the temperature-dependence of soil respiration, Functional Ecology, 8, 315-323.

Meehl, G. A., W. M. Washington, J. M. Arblaster, and A. Hu., 2004: Factors affecting climate sensitivity in global coupled models. J. Climate, 17, 1584-1596.

Monsrrud, R. A., 1990: Methods for comparing global vegetation maps, IIASA WP-9040, Int. Inst. For Appl. Syst. Anal., Laxenburg, Austria.

Maltrud, M. E., R. D. Smith, A. J. Semtner, and A. J. Malone, 1998: Global eddyresolving ocean simulations driven by 1985-1995 atmospheric winds, J. Geophys. Res. 103, 30825-30853.

Marland G, T. Boden, and R. Andres, 2002: Global, regional, and national annual CO2 emissions from fossil-fuel burning, cement production and gas flaring: 17511999, CDIAC NDP-030, Carbon Dioxide Information Analysis Center, Oak Ridge National Laboratory, Tennessee.

McGuire, A. D., S. Sitch, J. S. Clein, R. Dargaville, G. Esser, J. Foley, M. Heimann, F. Joos, J. Kaplan, D. W. Kicklighter, R. A. Meier, J. M. Melillo, B. Moore III, I. C. Prentice, N. Ramankutty, T. Reichenau, A. Schloss, H. Tian, L. J. Williams, and U. Wittenberg, 2001: Carbon balance of the terrestrial biosphere in the twentieth century: Analyses of $\mathrm{CO} 2$, climate and land-use effects with four process-based ecosystem models. Global Biogeochemical Cycles 15, 183-206.

Murphy, J. M., 1995: Transient response of the Hadley Centre coupled ocean-atmosphere model to increasing carbon dioxide: Part III. Analysis of global-mean response using simple models, J. Climate, 8, 496-514. 
UCRL-JRNL-209851

Nadelhoffer, K. J., B. A. Emmett, P. Gundersen, and Coauthors, 1999: Nitrogen makes a minor contribution to carbon sequestration in temperate forests, Nature 398, 145 148.

Najjar, R.G., and J. C. Orr, 1999: Biotic How-To, Revision 1.7, Ocean Carbon-cycle Model Intercomparison Project (OCMIP), http://www.ipsl.jussieu.fr/OCMIP/phase2/simulations/Biotic/HOWTOBiotic.html

Orr, J. C., and J.-C. Dutay, 1999: OCMIP mid-project workshop. Research GAIM Newsletter, 3. 4-5.

Orr, J. C., E. Maier-Raimer, U. Mikolajewicz, P. Monfray, J. L. Sarmiento, J. L., and Coauthors, 2001: Estimates of anthropogenic carbon uptake from four 3-D global ocean models. Global Biogeochemical Cycles 15, 43-60.

Owensby, C.E., J.M. Ham, A.K. Knapp and L.M. Auen, 1999: Biomass production and species composition change in a tall grass prairie ecosystem after long-term exposure to elevated atmospheric $\mathrm{CO}_{2}$, Global Change Biology, 5, 497-506.

Prentice, I. C., M. Heimann, and S. Sitch, 2000: The carbon balance of the terrestrial biosphere; ecosystem models and atmospheric observations, Ecological Applications 10 (6), 1553-1573.

Prentice, I. C., and Coauthors, 2001: Climate Change 2001: The Scientific Basis: Contribution of Working Group I to the Third Assessment Report of the IPCC, J.T. Houghton et al. (Eds.) Cambridge University Press, UK, pp. 183-237.

Ramankutty N, J. A., Foley, J. Norman and K. McSweeney, 2002: The global distribution of cultivable lands: current patterns and sensitivity to possible climate change. Global Ecology and Biogeography, 11, 377-392.

Root, T.L. and S. H. Schneider, 1993: Can large scale climatic models be linked with 
multiscale ecological studies? Conservation Biology 7(2), 256-270.

Sabine, C.L., and Coauthors, 2004: The oceanic sink for anthropogenic $\mathrm{CO}_{2}$, Science, $305,367-371$.

Sarmiento, J. L., and C. Le Quere, 1996: Oceanic carbon dioxide uptake in a model of century-scale global warming, Science 274, 1346-1350.

Sarmiento, J. L., T. C. Hughes, R. J. Stouffer, and S. Manabe, 1998: Simulated response of the ocean carbon cycle to anthropogenic climate warming, Nature 393, 245249.

Schimel, D. S., 1998: The Carbon equation, Nature 393, 208-209.

Senior, C. A., and J. F. B. Mitchell 2000: The time dependence of climate sensitivity, Geophys. Res. Lett., 27, 2685-2688.

Shaw, M.R., and Coauthors, 2002: Grassland responses to global environmental changes suppressed by elevated $\mathrm{CO}_{2}$. Science, 298, 1987-1990.

Thompson, S., B. Govindasamy, A. Mirin, K. Caldeira, C. Delire, J. Milovich, M. Wickett, and D. Erickson, 2004: Geophys. Res. Lett., 31(23), L23211.

Tjoelker, M.G., J. Oleksyn and P.B. Reich, 2001: Modelling respiration of vegetation: evidence for a general temperature-dependent Q(10), Global Change Biology, 7, 223-230.

Washington, W. M., J. W. Weatherly and Coauthors, 2000: Parallel Climate Model (PCM) control and transient simulations, Climate Dynamics 16, 755-774.

Zeng, N., H. Qian, E. Munoz, and R. Iacono, How strong is carbon cycle-climate feedback under global warming?, 2004: Geophys. Res. Lett., 31,, doi: 10.1029/ 2004GL020904. 
UCRL-JRNL-209851

\section{Figure captions}

Figure 1 Rate of fossil fuel emissions, land use change emissions and total emissions (top panel) and cumulative emissions (bottom panel) used in our simulations. Total emission rates reach peak values around year 2120.

Figure 2. Evolution of global- and annual-mean surface temperature (upper panel) and atmospheric $\mathrm{CO}_{2}$ concentration (lower panel). Surface temperature warming is about $8 \mathrm{~K}$ and atmospheric $\mathrm{CO}_{2}$ concentration is 1423 ppmv at year 2300 .

Figure 3 Evolution of radiative forcing (upper panel), and the global- and annual-mean surface temperature change in the coupled A2 simulation as a function of radiative forcing (lower panel). The amount of warming is much larger during the second half of the forcing than in the first half because of the thermal lag of the climate system and an increase in climate sensitivity with time (or warming).

Figure 4 "Effective" climate sensitivity as a function of time (upper panel), and as a function of surface temperature change (lower panel). Here, climate sensitivity is defined as the amount of warming per doubling of $\mathrm{CO}_{2}$. The signal to noise ratio is much improved after year 2050 (or after a warming of $2 \mathrm{~K}$ ). Climate sensitivity is seen to increase from about $2 \mathrm{~K}$ to $3 \mathrm{~K}$ as the simulation progresses, an increase of about $50 \%$. Figure 5 Evolution of the 5-yr running mean of global, annual flux of carbon from land to atmosphere (upper panel) and from ocean to atmosphere (lower panel). Negative values represent fluxes into land and ocean. Land fluxes show a dramatic reversal after year 2100 and ocean fluxes also decrease slightly after year 2100.

Figure 6 Evolution of Net Primary Productivity (NPP) and heterotrophic (soil microbial) respiration (upper panel), changes in vegetation biomass and soil carbon content (middle panel), and the turnover time of the biomass and soil carbon pools (lower panel). Though the turnover time of soil carbon declines dramatically, it does not become smaller than the turnover time of biomass and hence the land always remains a net sink. 
UCRL-JRNL-209851

Figure 7 Evolution of cumulative carbon emissions, uptakes by land and oceans, and the amount of carbon that stays in the atmosphere since the pre-industrial period in the fully coupled experiment.

Figure 8 Vegetation distributions in our simulations. Antarctica is not shown. The area covered by tropical and temperate forests increases dramatically when global warming increases by year 2300. There is also a migration of tropical, temperate, and boreal forests pole ward with warming, leading to significant declines in area occupied by tundra and polar deserts (land ice). 
Table 1 Changes in global and annual mean model results in coming centuries for A2 Scenario (e.g. decade of 1991-2000 minus $1891-1900$ refers to $20^{\text {th }}$ century climate change). Percentage changes are computed relative to the decade of 1891-1900. All variables except $\mathrm{CO}_{2}$ have been corrected for the drift in the control.

\begin{tabular}{l|lllllll}
\hline Period & Surface & Precip. & Water vapor & Sea ice & Sea ice & TOA & $\mathrm{CO}_{2}$ \\
& $\begin{array}{l}\text { Temp. } \\
(\%)\end{array}$ & $\left(\mathrm{kgm}^{-2}\right)(\%)$ & extent & volume & flux & $(\mathrm{ppmv})$ \\
& $(\mathrm{K})$ & & & $(\%)$ & $(\%)$ & $\left(\mathrm{Wm}^{-2}\right)$ & \\
\hline $20^{\text {th }}$ century & 0.80 & 1.6 & $1.12(5.3)$ & -7.4 & -28.6 & 0.46 & 77 \\
$21^{\text {st }}$ century & 2.70 & 4.1 & $4.03(19.0)$ & -25.1 & -50.6 & 0.93 & 344 \\
$22^{\text {nd }}$ century & 3.18 & 4.8 & $4.85(22.8)$ & -42.6 & -27.1 & 0.01 & 621 \\
$23^{\text {rd }}$ century & 1.15 & 1.9 & $1.86(4.1)$ & -15.0 & -14.1 & -0.58 & 99 \\
Total change & 7.83 & 12.4 & $11.86(52.2)$ & -90.1 & -120.4 & 0.82 & 1141 \\
\hline
\end{tabular}

Table 2: Carbon cycle feedback factors for the period from year 1870 to 2000, 2100, 2200 and 2300.

\begin{tabular}{l|lll}
\hline Year & $\mathrm{CO}_{2}$ in uncoupled & $\mathrm{CO}_{2}$ in coupled A2 & Carbon Cycle \\
& run (ppmv) & Scenario (ppmv) & Feedback Factor \\
\hline 1870 & 289 & 289 & - \\
2000 & 360 & 366 & 1.09 \\
2100 & 681 & 732 & 1.13 \\
2200 & 1155 & 1341 & 1.22 \\
2300 & 1166 & 1423 & 1.29 \\
\hline
\end{tabular}


UCRL-JRNL-209851

Table 3: Total emissions and its partitioning between various reservoirs for each century.

Numbers in brackets represent the percent of the partitioning

\begin{tabular}{l|lllll}
\hline Reservoir & $20^{\text {th }}$ Century & $21^{\text {st }}$ Century & $22^{\text {nd }}$ Century & $23^{\text {rd }}$ Century & Total since 1870 \\
\hline Emissions & 385.1 & 1790.6 & 2557.6 & 644.7 & 5404 \\
Land & $160.7(41.7)$ & $746.8(41.7)$ & $906.4(35.4)$ & $243.9(37.8)$ & $2067(38.3)$ \\
Ocean & $71.7(18.6)$ & $269.2(15.0)$ & $350.0(13.7)$ & $224.4(34.8)$ & $921(17.0)$ \\
Atmosphere & $153.0(39.7)$ & $777.2(43.3)$ & $1289.0(50.9)$ & $174.0(27.4)$ & $2416(44.7)$ \\
\hline
\end{tabular}

Table 4: Fraction of land area occupied by vegetation types at the end of centuries (e.g. $20^{\text {th }}$ century vegetation refers to the dominant vegetation during 1971-2000)

\begin{tabular}{l|llll}
\hline Vegetation type & $20^{\text {th }}$ century & $21^{\text {st }}$ century & $22^{\text {nd }}$ century & $23^{\text {rd }}$ century \\
\hline Tropical forests & 22.9 & 24.6 & 32.8 & 34.1 \\
Temperate forests & 21.1 & 24.3 & 29.7 & 30.5 \\
Boreal forests & 7.9 & 10.6 & 7.4 & 7.0 \\
Savanna, Grasslands \& & 11.8 & 11.8 & 10.1 & 10.2 \\
Shrub lands & & & & \\
Tundra & 7.7 & 6.5 & 2.7 & 1.8 \\
Desert & 15.3 & 12.3 & 11.3 & 11.6 \\
Polar desert & 13.3 & 7.9 & 6.0 & 4.8 \\
\hline
\end{tabular}


UCRL-JRNL-209851

Figure 1

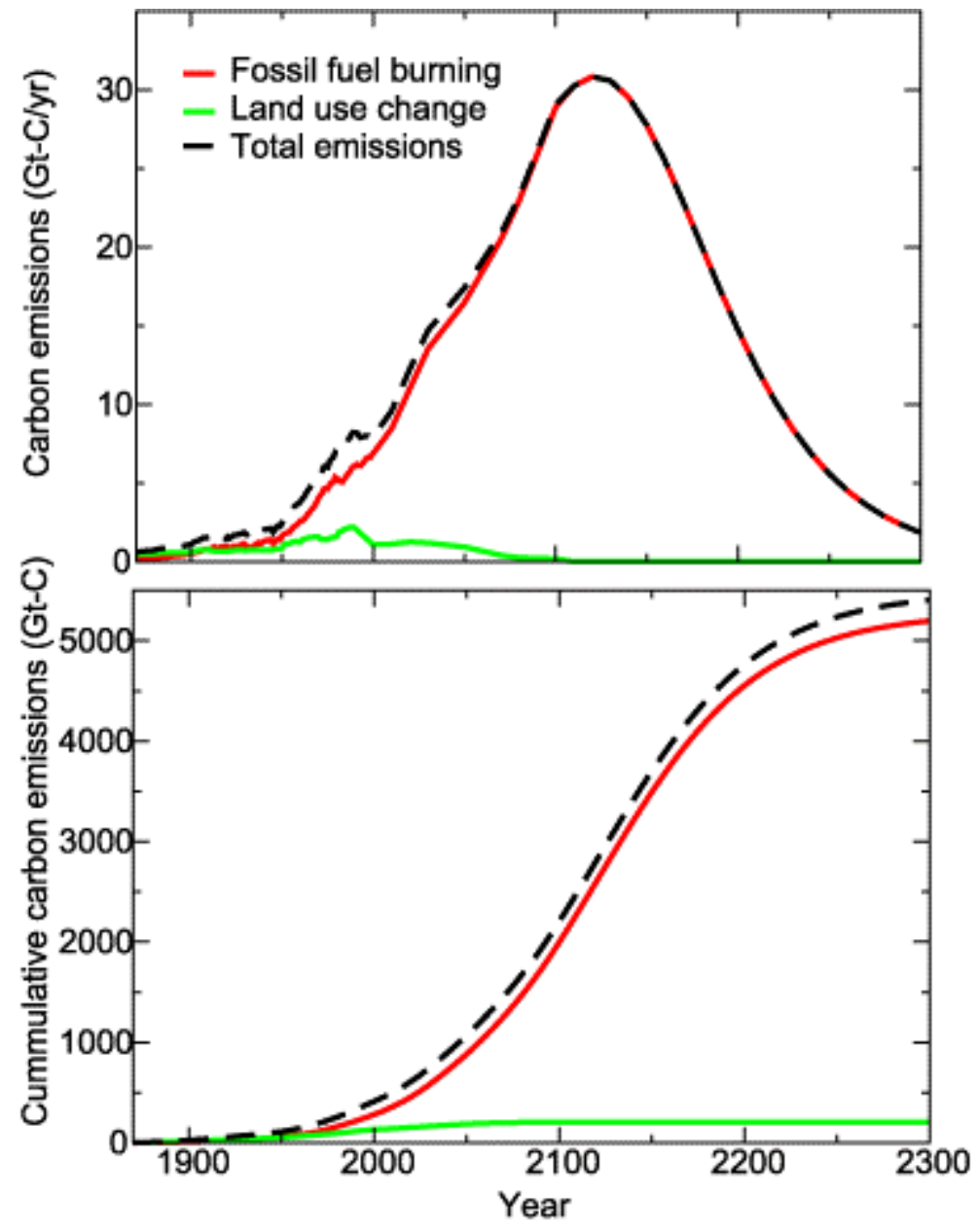


UCRL-JRNL-209851

Figure 2
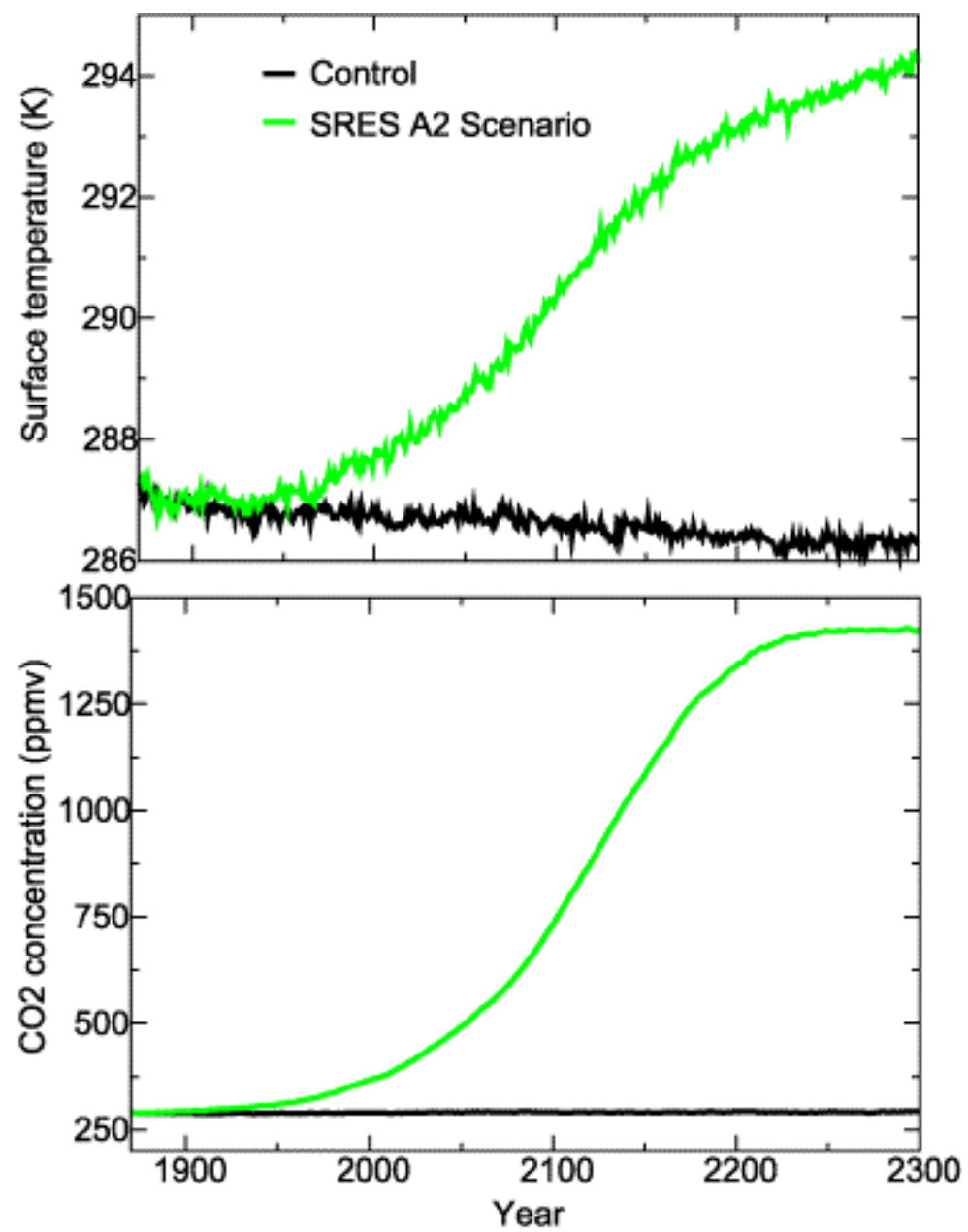
UCRL-JRNL-209851

Figure 3
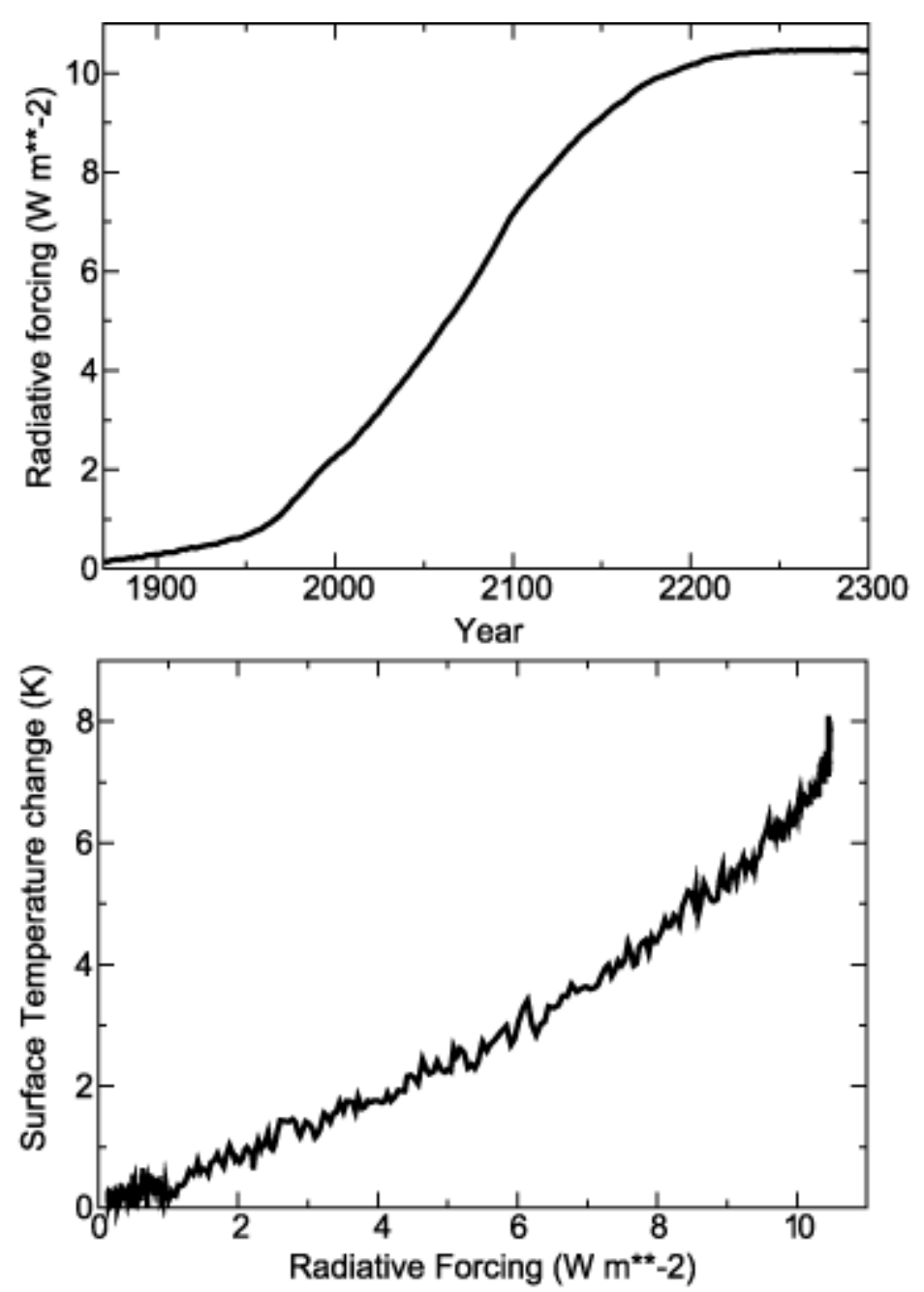
UCRL-JRNL-209851

Figure 4
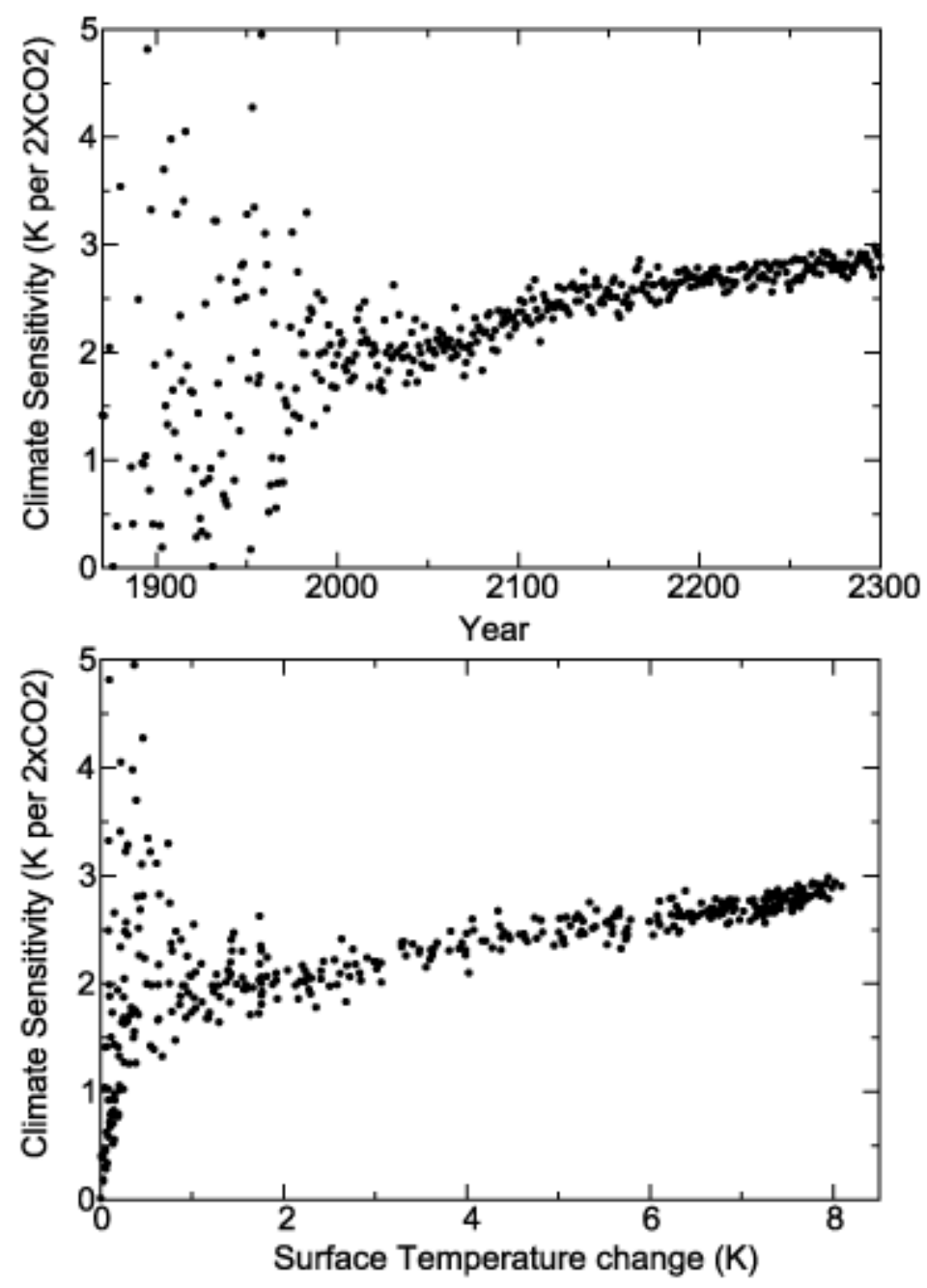
UCRL-JRNL-209851

Figure 5

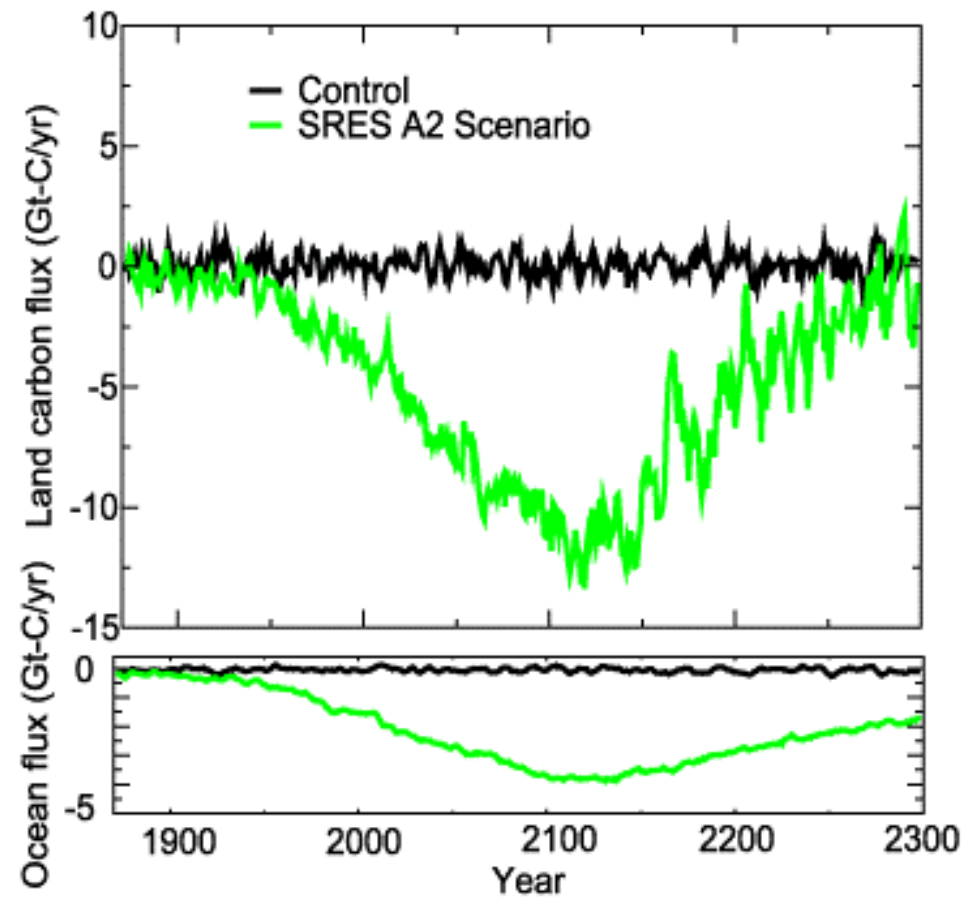




\section{Figure 6}
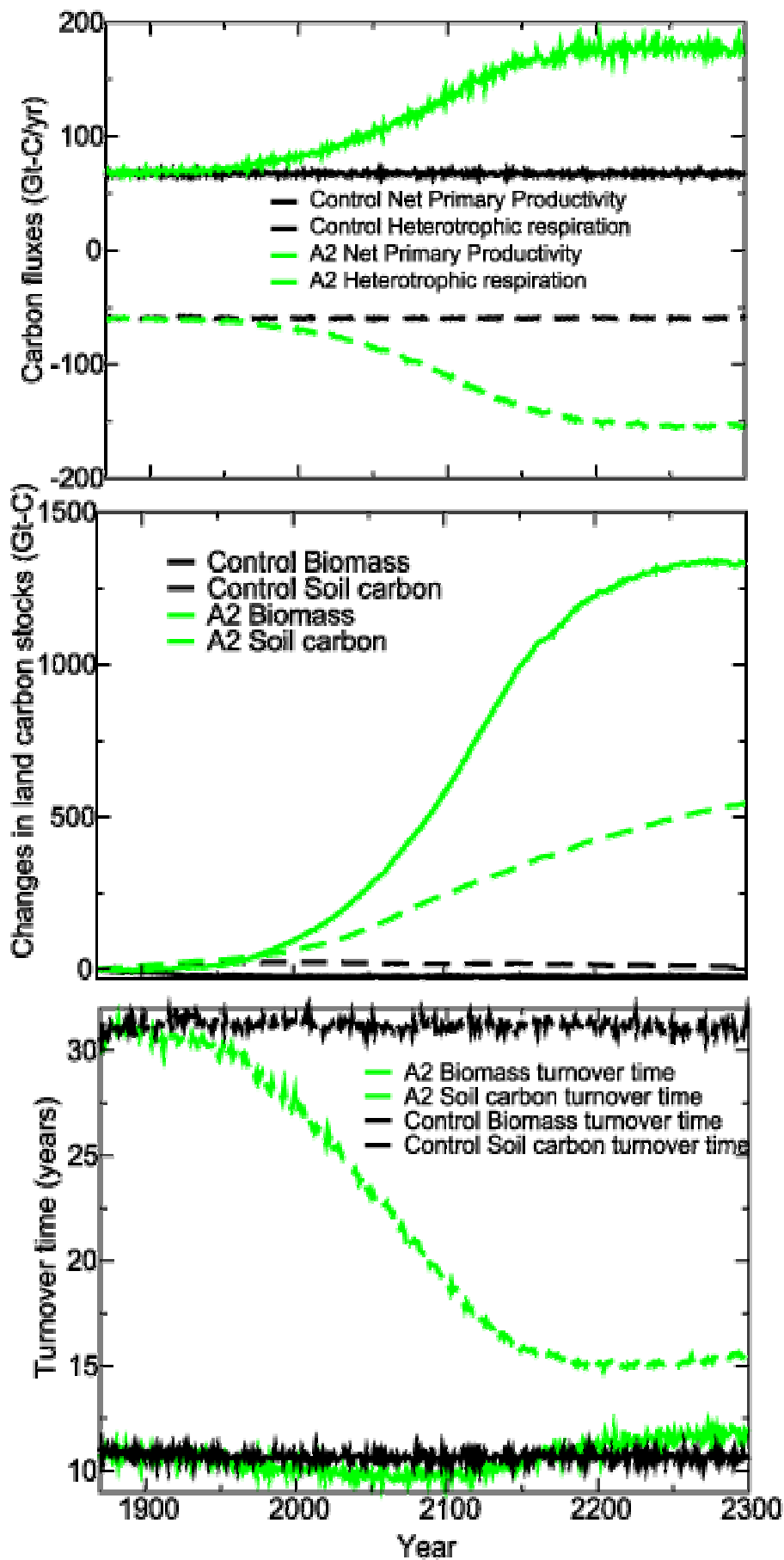
UCRL-JRNL-209851

Figure 7

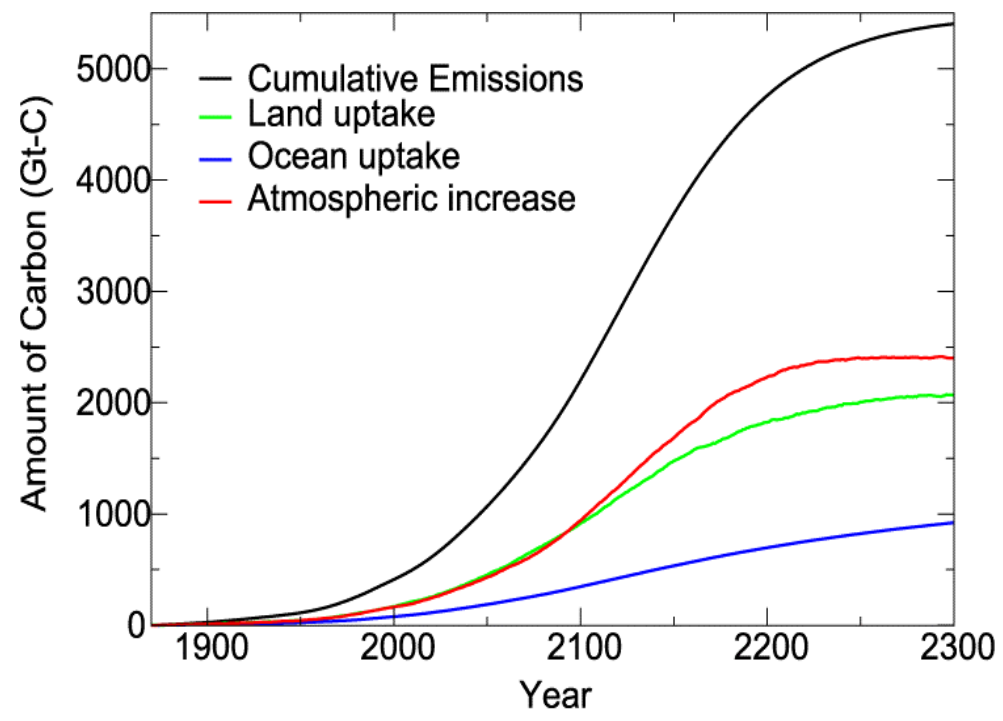


Figure 8

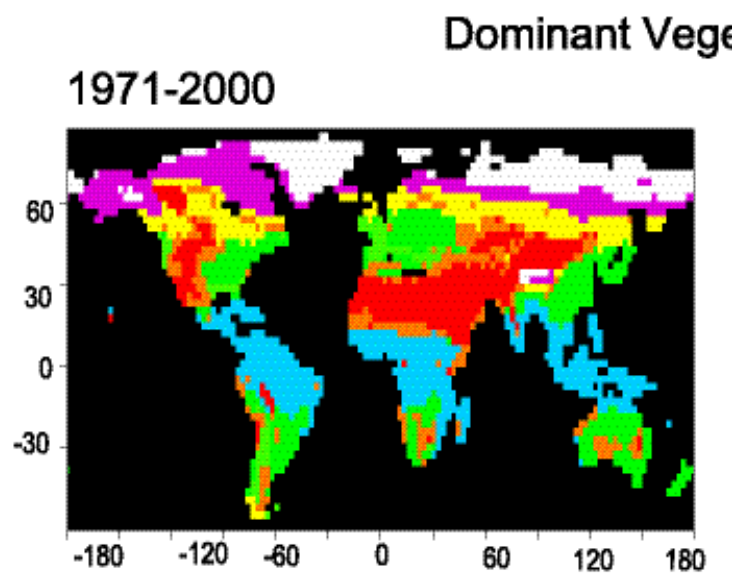

\section{ation Types}
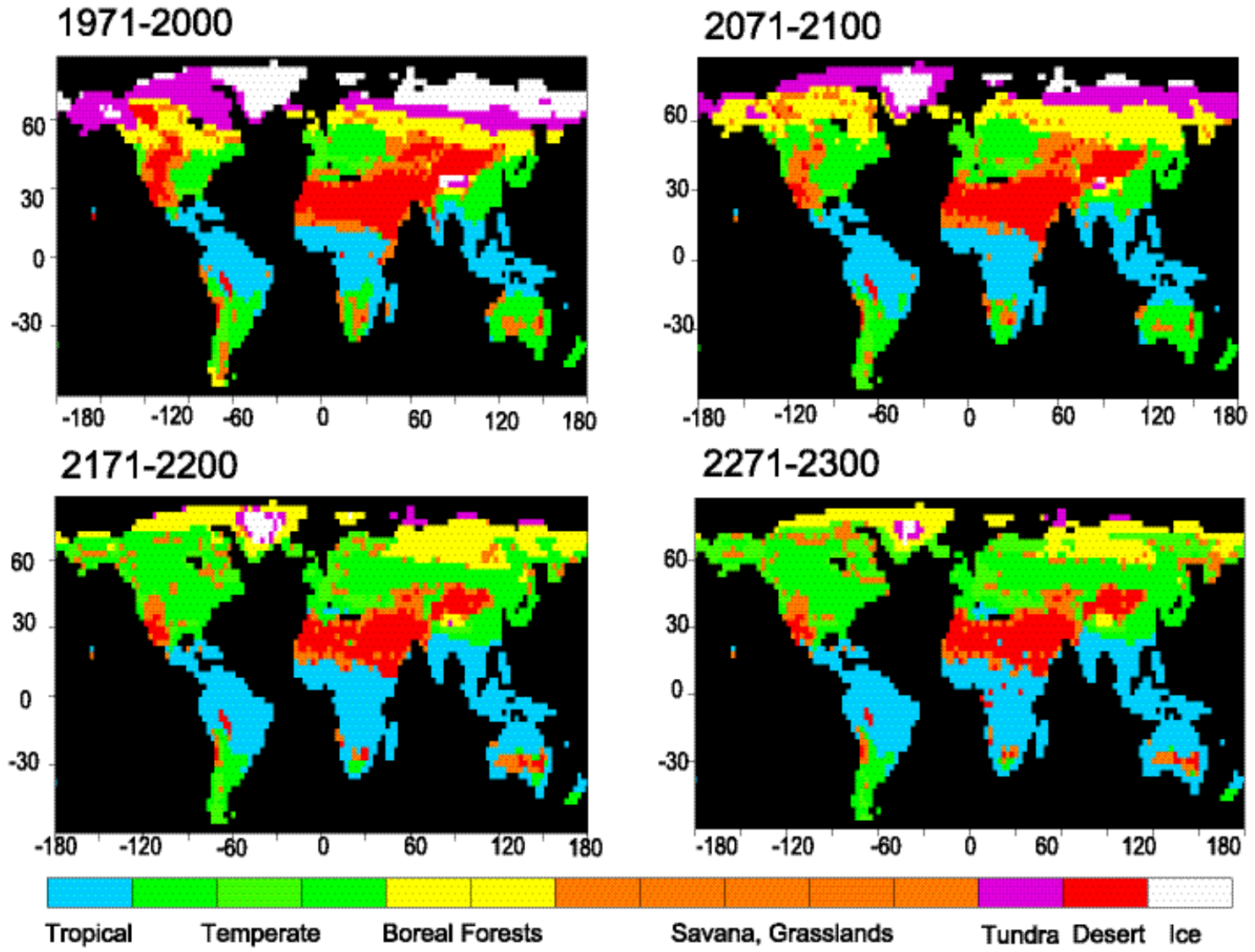